Supporting Information

\title{
Expansion of Ion Effects on Water Induced by a High Hydrophilic Surface of a Polymer Network
}

\author{
Ki Chul Park and Takehiko Tsukahara*
}

Laboratory for Advanced Nuclear Energy, Institute of Innovative Research, Tokyo Institute of Technology, 2-12-1-N1-6 O-okayama, Meguro-ku, Tokyo 152-8550, Japan.

*E-mail: ptsuka@ lane.iir.titech.ac.jp

This supporting information contains:

Number of pages: 12

Number of figures: 3

Number of Tables: 1

\section{Table of Contents}

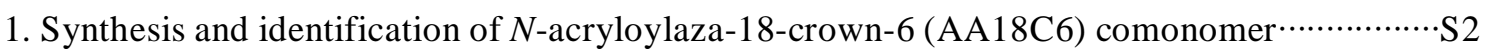

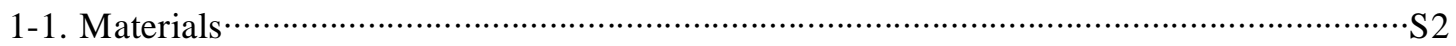

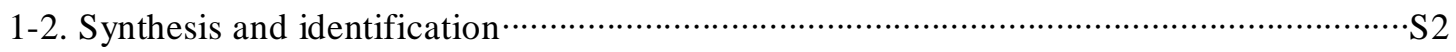

2. ATR-FTIR spectroscopic identification of PNIPAAm and poly(NIPAAm-co-AA18C6)

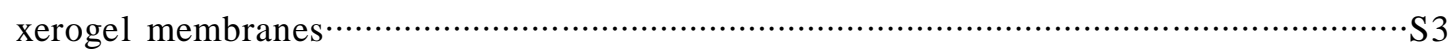

3. Swelling equilibria of PNIPAAm and poly(NIPAAm-co-AA18C6) hydrogel membranes $\cdots \cdots \cdot$ S4

4. Calculation procedure of osmotic coefficients $\phi$ at any temperature and osmotic pressures $\cdots \cdots \cdot \mathrm{S} 4$

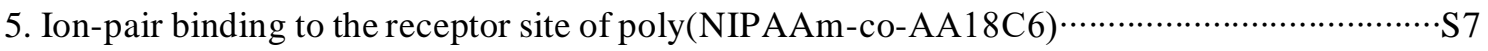

6. Comparison of ion-sensing results for PNIPAAm and poly(NIPAAm-co-AA18C6) hydrogel

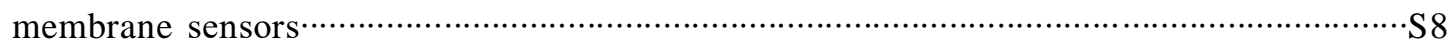

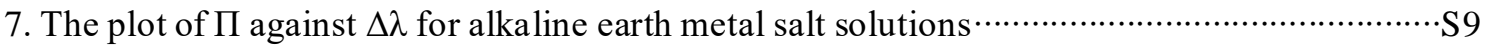

8. References 
1. Synthesis and identification of $N$-acryloylaza-18-crown-6 (AA18C6) comonomer

\section{1-1. Materials}

Acryloyl chloride (>98.0\%, stabilized with phenothiazine, Tokyo Chemical Industries Co., Ltd.) was purified by distillation under reduced pressure $\left(390 \mathrm{mmHg}\right.$, heating temperature: $\left.80^{\circ} \mathrm{C}\right)$ for removal of the stabilizer just before use. 1-Aza-18-crown-6 (>98.0\%, Tokyo Chemical Industries Co., Ltd.) and triethylamine (>99.0\%, Kanto Chemical Co., Inc.) were used as received. All other chemicals (purchased from Kanto Chemical Co., Inc.) were reagent grade and used without any purification.

\section{1-2. Synthesis and structural identification}

$\mathrm{N}$-acryloylaza-18-crown-6 (AA18C6) comonomer was synthesized by acylation of the secondary amino groups of the azacrown ether with acryloyl chloride. 1-Aza-18-crown-6 (3.80 mmol, $1.00 \mathrm{~g}$ ) was dissolved in dehydrated tetrahydrofuran (THF, $40 \mathrm{~mL}$ ) in a 1-L three-neck round-bottom flask fitted with a dropping funnel and a nitrogen inlet. Triethylamine $(3.80 \mathrm{mmol}$, $0.384 \mathrm{~g})$ dissolved in dehydrated THF $(20 \mathrm{~mL})$ was added to the solution. The mixed solution was maintained in an inert atmosphere by purging with dry nitrogen gas. Acryloyl chloride (3.80 mmol, $0.344 \mathrm{~g})$ dissolved in dehydrated THF $(15 \mathrm{~mL})$ was added dropwise at room temperature for $30 \mathrm{~min}$. The reaction mixture was heated at $40^{\circ} \mathrm{C}$ with vigorous stirring for $1 \mathrm{~h}$. The resulting triethylamine hydrochloride was removed by suction filtration, and the filtrate was evaporated under reduced pressure to obtain a clear yellow oil. The oily product was redissolved in chloroform $\left(\mathrm{CHCl}_{3}, 100 \mathrm{~mL}\right)$ and washed with distilled water $(100 \mathrm{~mL})$. The $\mathrm{CHCl}_{3}$ solution was dried with magnesium sulfate and suction-filtered. The filtrate was evaporated under reduced pressure to obtain a clear yellow oil. The crude product was purified by silica gel chromatography $\left(\mathrm{CHCl}_{3}\right.$ : methanol, 10:1) to give AA18C6 (1.08 g, yield: 89.9\%) as a clear colorless oil.

The structural identification of the purified product was conducted by proton and carbon-13 nuclear magnetic resonance $\left({ }^{1} \mathrm{H}\right.$ and ${ }^{13} \mathrm{C}$ NMR) spectroscopy measurements (Figure $\mathrm{S} 1$ ). The NMR spectra were recorded on a JNM-ECX400P (JEOL Ltd.) spectrometer throughout all the synthesis experiments. The assignment of ${ }^{13} \mathrm{C}$ NMR spectrum was made in light of the ${ }^{1} \mathrm{H}-{ }^{13} \mathrm{C}$ heteronuclear correlation spectrum. The results of ${ }^{1} \mathrm{H}$ and ${ }^{13} \mathrm{C}$ NMR peak assignment are listed below.

${ }^{1} \mathrm{H}$ NMR (400 MHz, $\mathrm{CDCl}_{3}$, int. ref.; tetramethylsilane (TMS)): $\delta / \mathrm{ppm}=3.59-3.70(\mathrm{~m}, 24 \mathrm{H}$, $\left.12 \mathrm{CH}_{2}\right), 5.65\left(\mathrm{dd}, 1 \mathrm{H}, J=10.5,2.0 \mathrm{~Hz}, \mathrm{CH}=\mathrm{C} H_{\text {cis }} \mathrm{H}\right), 6.32(\mathrm{dd}, 1 \mathrm{H}, J=16.7,2.0 \mathrm{~Hz}$, $\left.\mathrm{CH}=\mathrm{CH} H_{\text {trans }}\right), 6.63\left(\mathrm{dd}, 1 \mathrm{H}, J=10.5,16.7 \mathrm{~Hz}, \mathrm{CH}=\mathrm{CH}_{2}\right)$. 
${ }^{13} \mathrm{C} \mathrm{NMR}\left(100 \mathrm{MHz}, \mathrm{CDCl}_{3}\right.$, int. ref.; TMS): $\delta / \mathrm{ppm}=47.6,49.2\left(\mathrm{NCH}_{2}\right.$ of azacrown ring), $69.8,70.0,70.5,70.6,70.7,70.8,70.9\left(\mathrm{OCH}_{2}\right.$ of azacrown ring), 127.9, 128.0 (C of vinyl group), $166.7(\mathrm{~N} C=\mathrm{O})$.

a

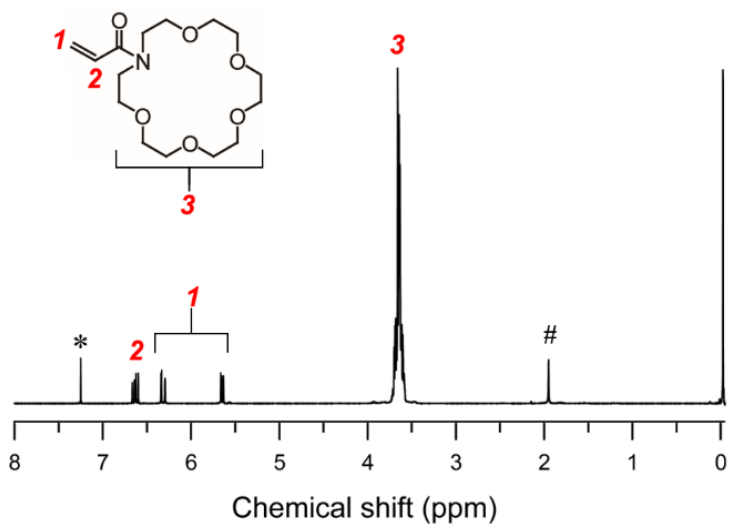

b

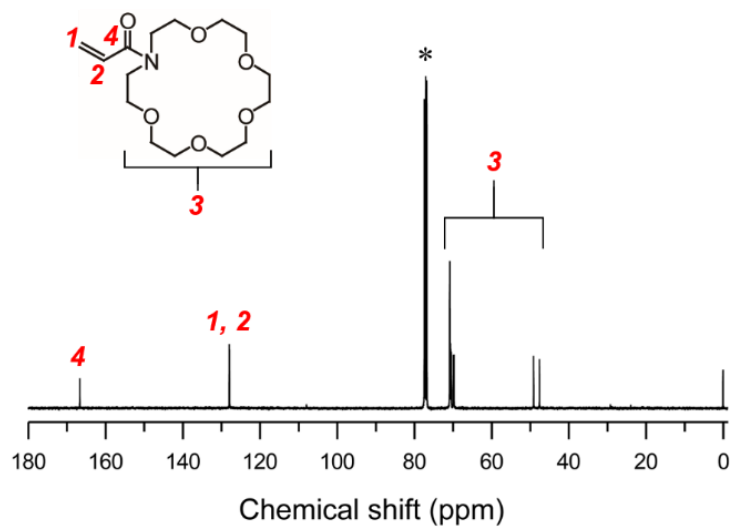

Figure S1. (a) ${ }^{1} \mathrm{H}$ and (b) ${ }^{13} \mathrm{C}$ NMR spectra of AA18C6 comonomers. The deuterated solvent used in the measurements; chloroform- $d$. Internal reference $(0 \mathrm{ppm})$; tetramethylsilane (TMS). (a) *chloroform, \#remaining solvent in synthesis. (b) *chloroform- $d$.

2. ATR-FTIR spectroscopic identification of PNIPAAm and poly(NIPAAm-co-AA18C6) xerogel membranes

Table S1. Assignment of ATR-FTIR peaks of PNIPAAm and poly(NIPAAm-co-AA18C6) xerogel membranes ${ }^{[1-6]}$

\begin{tabular}{l|l}
\hline $\begin{array}{c}\text { Wavenumber } \\
\left(\mathrm{cm}^{-1}\right)\end{array}$ & \multicolumn{1}{c}{ Assignment } \\
\hline 1113 & $v_{\text {as }} \mathrm{C}-\mathrm{O}$ of A18C6 rings \\
\hline 1172 & skeletal vibration of $-\mathrm{C}\left(\mathrm{CH}_{3}\right)_{2}$ \\
\hline 1367,1387 & sym. deformation of isopropyl $-\mathrm{CH}_{3}$ \\
\hline 1541 & amide-II band $(\mathrm{N}-\mathrm{H}$ bending vibration $)$ \\
\hline 1631 & amide-I band $($ hydrogen bonded $v \mathrm{C}=\mathrm{O})$ \\
\hline 2873 & $v_{\mathrm{s}} \mathrm{C}-\mathrm{H}$ of $-\mathrm{C}\left(\mathrm{CH}_{3}\right)_{2}$ \\
\hline 2971 & $v_{\text {as }} \mathrm{C}-\mathrm{H}$ of $-\mathrm{C}\left(\mathrm{CH}_{3}\right)_{2}$ \\
\hline 2932 & $v_{\text {as }} \mathrm{C}-\mathrm{H}$ of acrylamide backbone $-\mathrm{CH}_{2}-$ \\
\hline 3279 & $v \mathrm{~N}-\mathrm{H}$ of $2^{\circ}$-amide groups of acrylamides \\
\hline
\end{tabular}




\section{Swelling equilibria of PNIPAAm and poly(NIPAAm-co-AA18C6) hydrogel membranes}

As described in our previous report ${ }^{[7]}$, the reflection wavelength $(\lambda)$ of photonic crystal PNIPAAm hydrogel membrane sensors was red-shifted to a greater or less extent in the low concentration region $\left(0.03-0.3 \mathrm{~mol} \mathrm{~L}^{-1}\right.$ for alkali metal salts and $0.02-0.2 \mathrm{~mol} \mathrm{~L}^{-1}$ for alkaline earth metal salts) of all the chloride and nitrate salt solutions examined. The red shift $(\Delta \lambda<0)$ represents hydrogel swelling, which is ascribed to the Donnan equilibrium derived from specific ion adsorption on the charged surface of silica nanoparticles, i.e., the reverse osmosis caused by the concentration difference of mobile ions between the inside and outside of the hydrogel membrane. In swelling equilibria, the chemical potentials of all mobile components become equal in the coexisting two phases ${ }^{[8-10]}$. According to Flory-Rehner theory, the swelling equilibrium of charged hydrogel is described as $\Delta \prod_{\text {swelling }}=\Delta \Pi_{\text {mixing }}+\Delta \prod_{\text {elastic }}+\Delta \Pi_{\text {ion }}=0$, where the terms of the right side in turn represent polymer/solvent mixing contribution, elastic contribution due to the deformation of polymer network, and the contribution of ion/solvent mixing and electrostatic effects $^{[9,10]}$. The solvent is moved into or out of the hydrogel until the three mechanical forces to swell or contract the hydrogel are balanced to reach the equilibrium with the external phase ${ }^{[10]}$. As reported previously, the chloride and nitrate salt solutions of alkali metal cations exhibited the salting-out effect for PNIPAAm ${ }^{[11,12]}$. The salting-out effect should have an influence on the polymer-solvent mixing. In the PNIPAAm hydrogel membrane sensor, therefore, it is considered that the increase of $\Delta \prod_{\text {ion }}$ by the specific ion adsorption on the charged silica surface would have exceeded the decrease of $\Delta \Pi_{\text {mixing, }}$ causing the reverse osmotic swelling in the low salt concentration region. Then the three osmotic pressures continuously change until reaching the equilibrium of $\Delta \Pi_{\text {swelling }}=0$. To the contrary, the poly(NIPAAm-co-AA18C6) hydrogel membrane sensor showed the blue shift of reflection wavelength $(\Delta \lambda>0$, i.e., hydrogel contraction) in the same low concentration region of all the alkali salt solutions (Figure $3 \mathrm{C}$ (i), (ii) and Figure 4A). This suggests that the decrease of $\Delta \Pi_{\text {mixing }}$ would have exceeded the increase of $\Delta \Pi_{\text {ion }}$ derived from the specific ion adsorption on the silica surface, resulting in the deswelling of the copolymer hydrogel.

\section{Calculation procedure of osmotic coefficients $\phi$ at any temperature and osmotic pressures}

The osmotic pressure of real solutions, $\Pi(\mathrm{kPa})$, is calculated by correcting the van't Hoff's law $\left(\Pi_{0}=i C R T\right)$ with the osmotic coefficient $(\phi)$ of electrolyte solutions, as is shown by the following equaiton $(\mathbf{S 1})$ : 


$$
\Pi=\phi \Pi_{0}=\phi i C \mathrm{RT}
$$

where $i$ is the number of ions produced by dissociation of solutes, $C$ is the molar concentration of solutions $\left(\mathrm{mol} \mathrm{L}^{-1}\right), \mathrm{R}$ is universal gas constant $\left(8.31446 \mathrm{~N} \cdot \mathrm{m} \mathrm{mol}^{-1} \mathrm{~K}^{-1}\right.$ ), and $\mathrm{T}$ is absolute temperature $(\mathrm{K})$.

The osmotic coefficient is derived from the mean activity coefficient $\left(\gamma_{ \pm}\right)$of solutes through the Gibbs-Duhem relation between the solvent and solute activities. Thus far, various models have been proposed to predict accurately the thermodynamic properties of electrolyte solutions, providing the calculation methods of mean activity coefficients at $25^{\circ} \mathrm{C}$. The one-parameter or two-parameter models of Bromley ${ }^{[13]}$, Meissner ${ }^{[14-17]}$ and Pitzer ${ }^{[18-20]}$ have directly extended the Debye-Hückel (D-H) model based on long-range electrostatic ion-ion interactions for dilute solutions to enable the application to a higher concentration range of electrolyte solutions. These models are suitable for strong, single electrolyte solutions. In the present study, the osmotic experiments were conducted at $10{ }^{\circ} \mathrm{C}$. In terms of the strong temperature dependence of activity coefficients, it is required to consider the temperature effect for each electrolyte solution. In the present study, the Bromley model readily available for temperature effects was adopted for the calculation of osmotic coefficients at $10^{\circ} \mathrm{C}$. In the Bromley model, the osmotic coefficient at any temperature is directly calculated from ionic strengths $(I)$ by using the D-H constant $\left(A_{\gamma}\right)$ for activity coefficients and the characteristic Bromley parameters $(B)$ that takes temperature effects into account. The $B$ values for temperature effects can be calculated by utilizing the Meissner's method for reflecting the temperature effect to the activity coefficient. The Meissner's method derives the reduced activity coefficient $\left(\Gamma_{t}^{\circ}\right)$ at a given temperature for any ionic strength from the value at $25{ }^{\circ} \mathrm{C}$, converting it to the mean activity coefficient applicable to the Bromley model. The calculation of osmotic coefficient at any temperature is as described below.

The reduced activity coefficient, $\Gamma_{\mathrm{t}}^{\circ}$, for temperature, $t\left({ }^{\circ} \mathrm{C}\right)$, at a given ionic strength, $I$, can be calculated according to the Meissner equation $(\mathbf{S 2})^{[14,21]}$ :

$$
\log \Gamma_{\mathrm{t}}^{\circ}=(1.125-0.005 t) \log \Gamma_{25^{\circ} \mathrm{C}}^{\circ}-(0.125-0.005 t) \log \Gamma_{\mathrm{ref}}^{\circ}
$$

where $\Gamma^{\circ} 25^{\circ} \mathrm{C}$ is the reduced activity coefficient at $25^{\circ} \mathrm{C}$, and $\Gamma^{\circ}$ ref is the reference reduced activity coefficient defined as the following equation (S3).

$$
\log \Gamma_{\mathrm{ref}}^{\circ}=\frac{-0.41 \sqrt{I}}{1+\sqrt{I}}+0.039 I^{0.92}
$$

The reduced activity coefficient is defined as the equation (S4) represented by the mean molal activity coefficient, $\gamma_{ \pm}$, and the charge number of ions, $z+$ and $z^{\left[{ }^{[15-17]}\right.}$. 


$$
\Gamma^{\circ} \equiv \gamma_{ \pm}^{\frac{1}{z_{+} z_{-}}}
$$

The reduced activity coefficient at $25^{\circ} \mathrm{C}$ is calculated by combining the equation (S4) with the following Bromley equation (S5) for the mean activity coefficient of single electrolyte solutions ${ }^{[13]}$ :

$$
\log \gamma_{ \pm}=\frac{-A_{\gamma}\left|z_{+} z_{-}\right| \sqrt{I}}{1+\rho \sqrt{I}}+\frac{(0.06+0.6 B)\left|z_{+} z_{-}\right| I}{\left(1+\frac{1.5}{\left|z_{+} z_{-}\right|} I\right)^{2}}+B I
$$

where $\rho$ is a constant of D-H equation, which is related to the distance of closest approach of ions in solution, and $A_{\gamma}$ corresponds to the D-H constant for activity coefficients. The $\rho$ value at $25{ }^{\circ} \mathrm{C}$ for the salts with the valence type of $z_{+}-z_{-}=1-1,2-1,1-2,2-2,3-2$, and $1-4$ can be set to 1.0 , which is regarded as being independent of temperature. The values of $B$ for the specific electrolytes at $25{ }^{\circ} \mathrm{C}$ are listed in the Bromley's report ${ }^{[13]}$. The $A_{\gamma}$ is calculated according to the following equation $(\mathbf{S 6})^{[22]}$ :

$$
A_{\gamma}=\frac{1}{2.303}\left(\frac{e}{\sqrt{D \mathrm{kT}}}\right)^{3} \sqrt{\frac{2 \pi \mathrm{d}_{0} \mathrm{~N}_{\mathrm{A}}}{1000}}
$$

where $\mathrm{d}_{0}$ represents the solvent density at the given temperature, $\mathrm{T}(\mathrm{K}), D$ is the dielectric constant at $\mathrm{T}, \mathrm{k}$ is Boltzmann's constant $\left(1.38045 \times 10^{-16} \mathrm{erg} \mathrm{K}^{-1}\right), \mathrm{N}_{\mathrm{A}}$ is Avogadoro's number $\left(6.0232 \times 10^{23}\right)$, and $e$ represents electronic charge $\left(4.8029 \times 10^{-10}\right.$ e.s.u.). The reduced activity

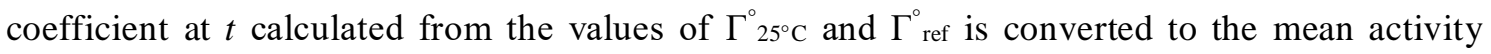
coefficient at the temperature by using the equation (S4). The $B$ value considering temperature effect is derived from the mean activity coefficient at the given temperature and ionic strength by using the Bromley equation (S5).

The $\phi$ value is calculated by using the equation of $(\mathbf{S 7})$ with the terms of $(\mathbf{S 8})$ and $(\mathbf{S 9})^{[13]}$ :

$$
\begin{gathered}
\left.\phi=1-2.303 A_{\gamma}\left|z_{+} z_{-}\right| \frac{\sqrt{I}}{3} \sigma\left(\rho I^{1 / 2}\right)+2.303(0.06+0.6 B)\left|z_{+} z_{-}\right| \frac{1}{2} \psi(a I)+2.303 B \frac{I}{2} \text { (S }\right) \\
\sigma\left(\rho I^{1 / 2}\right)=\frac{3}{\left(\rho I^{1 / 2}\right)^{3}}\left[1+\rho I^{1 / 2}-\frac{1}{1+\rho I^{1 / 2}}-2 \ln \left(1+\rho I^{1 / 2}\right)\right]
\end{gathered}
$$




$$
\psi(a I)=\frac{2}{a I}\left[\frac{1+2 a I}{(1+a I)^{2}}-\frac{\ln (1+a I)}{a I}\right]-2.303 B \frac{I}{2}
$$

Here, $a=1.5 /\left|z+z_{-}\right|$and, as above mentioned, $\rho=1.0$ are used. The $\phi$ value at the given temperature and ionic strength is calculated using the $B$ parameter for that temperature and ionic strength. The osmotic coefficient at $10{ }^{\circ} \mathrm{C}$ for each ionic strength was calculated according to the above Bromley and Meissner methods, and applied to the computation of osmotic pressure for all the alkali and alkaline earth salt solutions considered in the present study. The ionic strength was calculated from the molal concentration of salt solutions. The concentration unit conversion from molarity to molality was carried out by the interpolation of the fourth-order polynomial leastsquares fit curve for the plot of molality vs molarity based on the literature data for each electrolyte solution ${ }^{[23-28]}$. All the curves for the salt solutions considered in this study provided the determination coefficient $\mathrm{R}^{2}=1$.

\section{Ion-pair binding to the receptor site of poly(NIPAAm-co-AA18C6)}

The stability constants of crown-ether complexes with alkali and alkaline earth metal cations in polar organic solvents are two to five orders of magnitude higher than those in water ${ }^{[29]}$. Therefore, the recognition of ion pairs has commonly been carried out exclusively in organic solvents to stabilize the noncovalent interactions of cations and anions with charge-neutral receptors by avoiding intense competition with hydration of ions ${ }^{[30-32]}$. In the present study, the specific combinations of $\mathrm{Ca}^{2+}$ with $\mathrm{Cl}^{-}$and of $\mathrm{Sr}^{2+}$ with $\mathrm{NO}_{3}{ }^{-}$have enhanced the binding of the divalent cations to the A18C6 subunits in aqueous solutions, in contrast to the weak binding in $\mathrm{Ca}\left(\mathrm{NO}_{3}\right)_{2}$ and $\mathrm{SrCl}_{2}$ solutions (Figure $4 \mathrm{~B}$ (ii), (iii)). This suggests that inherently labile host-guest interactions in aqueous media are stabilized by concerted effect of the cations and anions bound to the receptor polymer, which would be due to a possible stabilization by electrostatic compensation for energetically unfavorable separation of cations and anions and the specific size matching of ion pairs to the receptor site ${ }^{[30-32]}$. Normally, however, the size matching of $\mathrm{Sr}^{2+}$ to the A18C6 macrocyclic cavity is higher than that of $\mathrm{Ca}^{2+}$ (ionic radii and cavity size: $\mathrm{Sr}^{2+}, 1.16$ $\AA^{[33]} ; \mathrm{Ca}^{2+}, 1.00 \AA^{[33]}, \mathrm{A} 18 \mathrm{C} 6,2.68 \AA^{[34]}$ ), similarly to that reported for 18-crown-6 (cavity radii: $1.34-1.43 \AA)^{[35,36]}$. Furthermore, in terms of hard-soft acid-base (HSAB) principle, compared to $\mathrm{Ca}^{2+}$, relatively soft $\mathrm{Sr}^{2+}$ forms a more stable complex with the A18C6 subunit of soft nitrogen atom-containing cavity ${ }^{[36]}$. Therefore, the more prominent recognition of $\mathrm{Ca}^{2+} / \mathrm{Cl}^{-}$than $\mathrm{Sr}^{2+} / \mathrm{NO}_{3}{ }^{-}$ opposite to the normal size matching and the HSAB principle suggests the higher size conformity of the $\mathrm{Ca}^{2+} / \mathrm{Cl}^{-}$ion pair with the receptor site of the copolymer. 
6. Comparison of ion-sensing results for PNIPAAm and poly(NIPAAm-co-AA18C6) hydrogel membrane sensors

The plots of reflection wavelength shift, $\Delta \lambda$, against salt concentrations $\left(\sim 3.0 \mathrm{~mol} \mathrm{~L}^{-1}\right)$ for PNIPAAm hydrogel membrane sensors were already reported in our previous report (Figure 1C in Ref. [7]). The same-scale plots of $\Delta \lambda$ for poly(NIPAAm-co-AA18C6) hydrogel membrane sensors are shown in Figure S2(a). The comparison of these $\Delta \lambda$ plots showed an overall tendency that the changing rate of $\Delta \lambda$ for the copolymer hydrogel membrane sensor in the salt concentration region higher than around $1.0 \mathrm{~mol} \mathrm{~L}^{-1}$ was lower than the PNIPAAm hydrogel membrane sensor in all the salt solutions examined. This tendency was more remarkable in the chloride salt solutions of structure-making cations, for example, $\mathrm{Li}^{+}$. Figure $\mathrm{S} 2$ (b) shows the direct comparison of the $\Delta \lambda$ plots in the salt solutions of $\mathrm{Li}^{+}$between PNIPAAm and poly(NIPAAm-co-AA18C6) hydrogel membrane sensors. The $\Delta \lambda$ variation with the increase of the salt concentration was more suppressed in the copolymer hydrogel membrane. Furthermore, the suppression degree was higher in the chloride salt solution than in the nitrate salt solution. The results indicate that the dehydration of the copolymer hydrogel membrane was more hindered than PNIPAAm hydrogel membrane by all the salts examined, particularly by the chloride salts of structure-making cations.

a

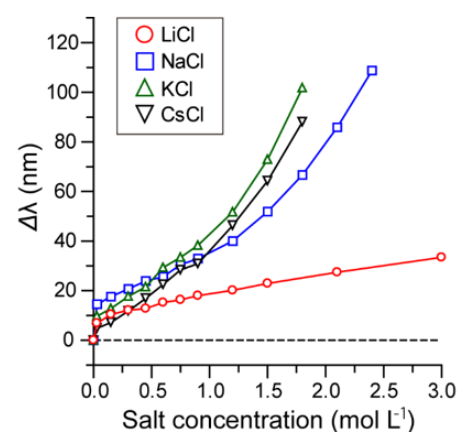
Salt concentration $\left(\mathrm{mol} \mathrm{L}^{-1}\right)$

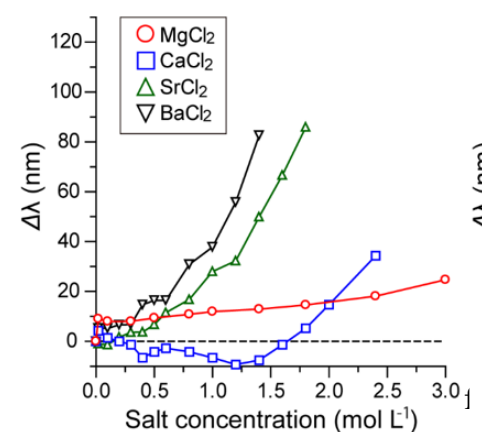

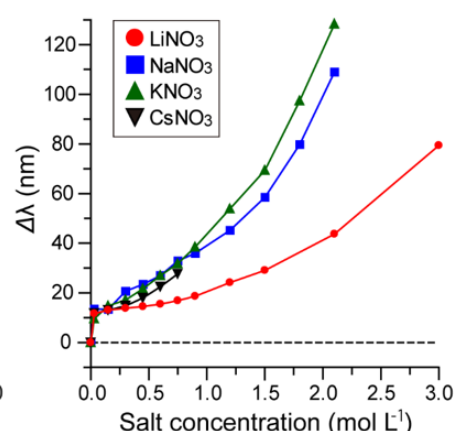

Salt concentration ( $\mathrm{mol} \mathrm{L}^{-1}$ )

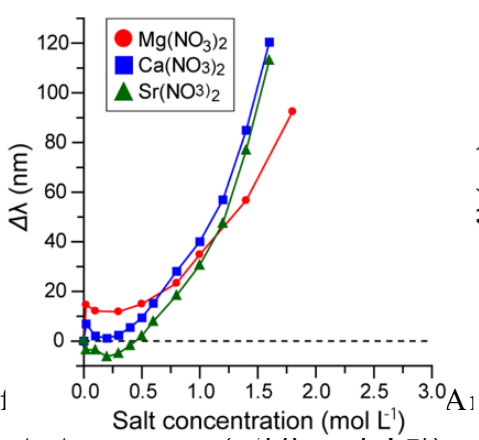

b
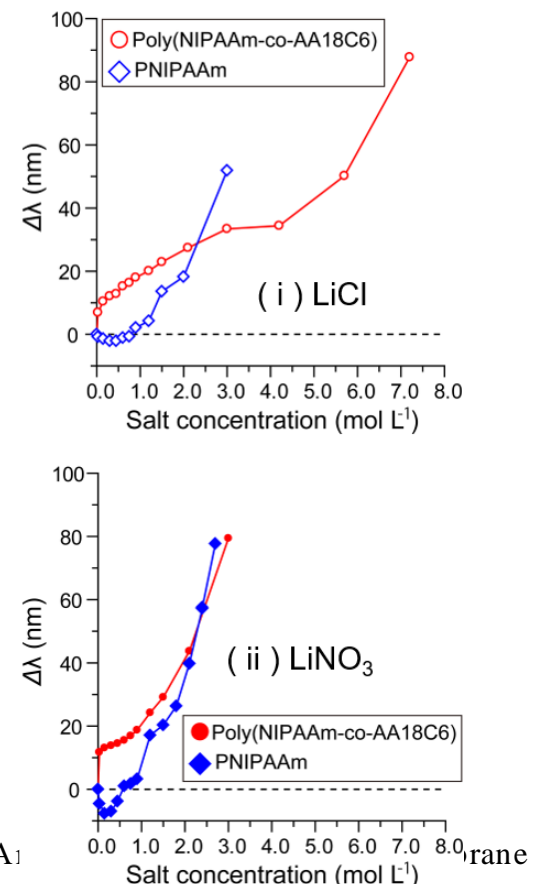
sensors in the same salt concentration range $\left(\sim 3.0 \mathrm{~mol} \mathrm{~L}^{-1}\right)$ as reported tor PNIPAAm hydrogel membrane sensor in Ref. [7]. (b) The superimposed $\Delta \lambda$ plots for PNIPAAm and poly(NIPAAm-coAA18C6) hydrogel membrane sensors in the chloride and nitrate salt solutions of $\mathrm{Li}^{+}$. 
7. The plot of $\Pi$ against $\Delta \lambda$ for alkaline earth metal salt solutions

Figure S3 shows the plot of the $\phi$-corrected $\Pi$ values at the given temperature of $10^{\circ} \mathrm{C}$ against $\Delta \lambda$ for the alkaline earth metal salt solutions.
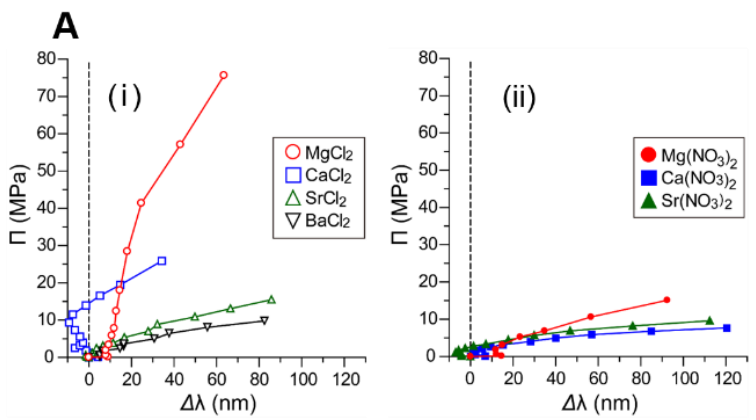

B
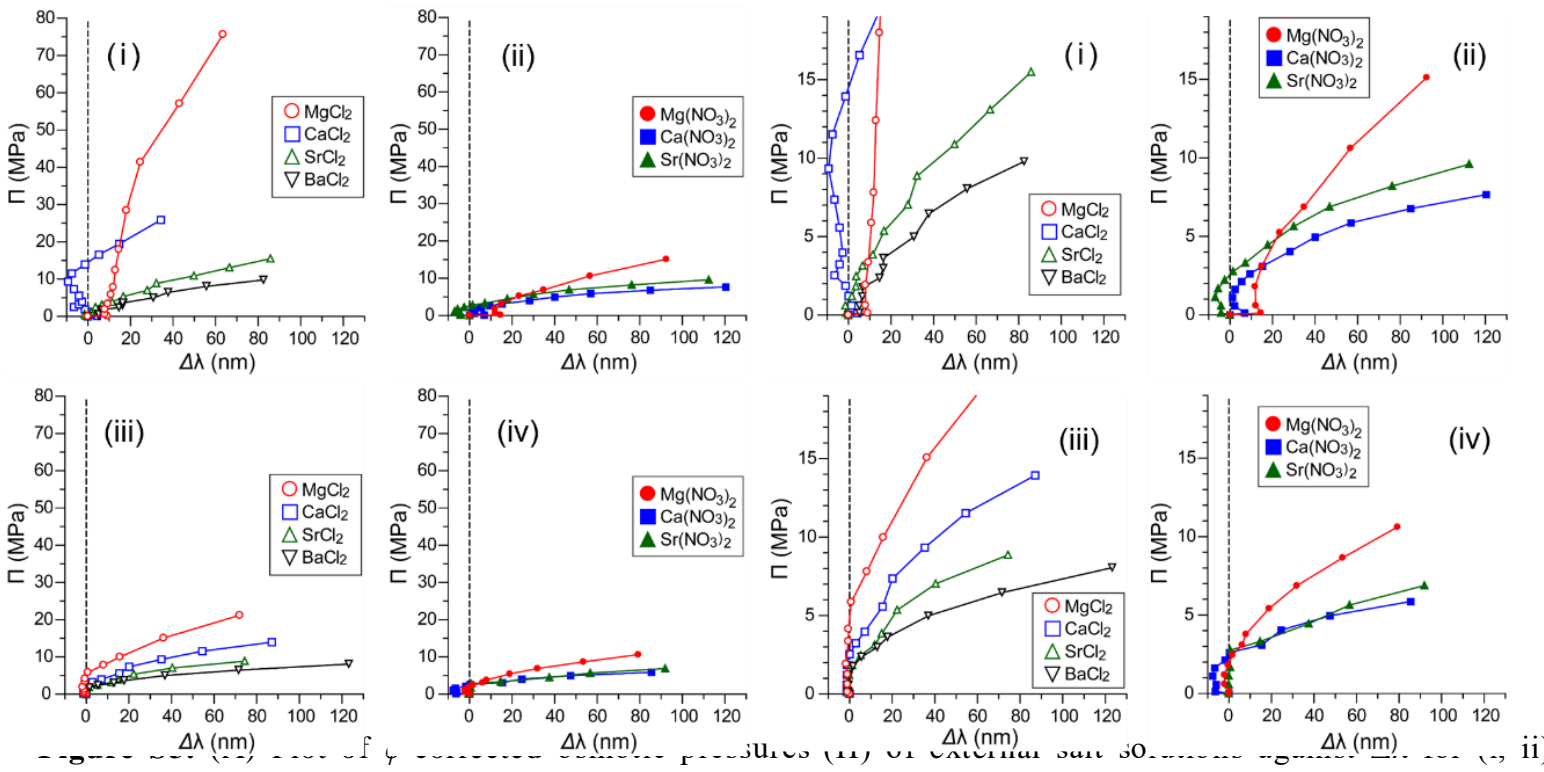

poly(NIPAAm-co-AA18C6) and (iii, iv) PNIPAAm hydrogel membrane sensors. (B) Enlarged view of (A).

\section{$\underline{\text { 8. References }}$}

[1] Tamirisa, P. A.; Koskinen, J.; Hess, D. W. Plasma polymerized hydrogel thin films. Thin Solid Films 2006, 515, 2618-2624.

[2] Hirashima, Y.; Sato, H.; Suzuki, A. ATR-FTIR spectroscopic study on hydrogen bonding of $\operatorname{poly}(N$-isopropylacrylamide-co-sodium acrylate) gel. Macromolecules 2005, 38, 9280-9286.

[3] Ju, X.-J.; Chu, L.-Y.; Mi, P.; Song, H.; Lee, Y. M. Synthesis and characterization of a novel thermo-sensitive copolymer of $\mathrm{N}$-isopropylacrylamide and dibenzo-18-crown-6-diacrylamide. Macromol. Rapid Commun. 2006, 27, 2072-2077. Supporting Information (http://www.wiley-vch.de/contents/jc_2263/2006/marc200600602_s.pdf). 
[4] Beattie, D. A.; Addai-Mensah, J.; Beaussart, A.; Franks, G. V.; Yeap, K.-Y. In situ particle film ATR FTIR spectroscopy of poly( $N$-isopropyl acrylamide) (PNIPAM) adsorption onto talc. Phys. Chem. Chem. Phys. 2014, 16, 25143-25151.

[5] Kalsi, P. S. Spectroscopy of Organic Compounds. New Age International Publisher. 2007. Chapt. 3. Infrared Spectroscopy (IR). pp 111-114.

[6] Katsumoto, Y.; Tanaka, T.; Sato, H.; Ozaki, Y. Conformational change of $\operatorname{poly}(N$ isopropylacrylamide) during the coil-globule transition investigated by attenuated total reflection/infrared spectroscopy and density functional theory calculation. J. Phys. Chem. A 2002, 106, 3429-3435.

[7] Park, K. C.; Tsukahara, T. Quantitative evaluation of long-range and cooperative ion effect on water in polyamide network. J. Phys. Chem. B 2019, 123, 2948-2955.

[8] Chang, R.; Kaplan, L. J. The Donnan equilibrium and osmotic pressure. J. Chem. Educ. 1977, $54,218-219$.

[9] Horkay, F.; Tasaki, I.; Basser, P. J. Osmotic swelling of polyacrylate hydrogels in physiological salt solutions. Biomacromolecules 2000, 1, 84-90.

[10] Baker, J. P.; Hong, L. H.; Blanch, H. W.; Prausnitz, J. M. Effect of initial total monomer concentration on the swelling behavior of cationic acrylamide-based hydrogels. Macromolecules 1994, 27, 1446-1454.

[11] Zhang, Y.; Furyk, S.; Bergbreiter, D. E.; Cremer, P. S. Specific ion effects on the water solubility of macromolecules: PNIPAM and the Hofmeister series. J. Am. Chem. Soc. 2005, $127,14505-14510$.

[12] Inomata, H.; Goto, S.; Otake, K.; Saito, S. Effect of additives on phase transition of $N$ Isopropylacrylamide gels. Langmuir 1992, 8, 687-690.

[13] Bromley, L. A. Thermodynamic properties of strong electrolytes in aqueous solutions. AIChE J. 1973, 19, 313-320.

[14] Meissner, H. P.; Peppas, N. A. Activity coefficients-aqueous solutions of polybasic acids and their salts. AIChE J. 1973, 19, 806-809.

[15] Meissner, H. P.; Tester, J. W. Activity coefficients of strong electrolytes in aqueous solutions. Ind. Eng. Chem. Process Des. Develop. 1972, 11, 128-133.

[16] Meissner, H. P.; Kusik, C. L. Activity coefficients of strong electrolytes in multicomponent aqueous solutions. AIChE J. 1972, 18, 294-298.

[17] Meissner, H. P.; Kusik, C. L.; Tester, J. W. Activity coefficients of strong electrolytes in aqueous solution-effect of temperature. AIChE J. 1972, 18, 661-662. 
[18] Silvester, L. F.; Pitzer, K. S. Thermodynamics of electrolytes. 8. High-temperature properties, including enthalpy and heat capacity, with application to sodium chloride. J. Phys. Chem. 1977, 81, 1822-1828.

[19] Pitzer, K. S.; Mayorga, G. Thermodynamics of electrolytes. II. Activity and osmotic coefficients for strong electrolytes with one or both ions univalent. J. Phys. Chem. 1973, 77, 2300-2308.

[20] Silvester, L. F.; Pitzer, K. S. Thermodynamics of electrolytes. X. Enthalpy and the effect of temperature on the activity coefficients. J. Solution Chem. 1978, 7, 327-337.

[21] Zemaitis, Jr., J. F.; Clark, D. M.; Rafal, M.; Scrivner, N. C. Handbook of Aqueous Electrolyte Thermodynamics: Theory \& Application (American Institute of Chemical Engineers, Inc. 1986), Chap. IV, pp.84-89.

[22] Zemaitis, Jr., J. F.; Clark, D. M.; Rafal, M.; Scrivner, N. C. Handbook of Aqueous Electrolyte Thermodynamics: Theory \& Application (American Institute of Chemical Engineers, Inc. 1986), Chap. IV, pp.48-55.

[23] Lide, D. R., ed. CRC Handbook of Chemistry and Physics, Internet Version 2005, Section 8, pp 58-84, CRC Press, Boca Raton, FL, 2005. The molality and molarity for the salt solutions of $\mathrm{LiCl}, \mathrm{NaCl}, \mathrm{KCl}, \mathrm{CsCl}, \mathrm{MgCl}_{2}, \mathrm{CaCl}_{2}, \mathrm{SrCl}_{2}, \mathrm{BaCl}_{2}, \mathrm{NaNO}_{3}$, and $\mathrm{KNO}_{3}$ were cited.

[24] Pearce, J. N.; Nelson, A. F. The vapor pressures of aqueous solutions of lithium nitrate and the activity coefficients of some alkali salts in solutions of high concentration at $25^{\circ} . \mathrm{J}$. Am. Chem. Soc. 1932, 54, 3544-3555. The molality and density of $\mathrm{LiNO}_{3}$ were cited from this literature, and the molality was converted to the molarity by using the density.

[25] Merton, T. R. The viscosity and density of caesium nitrate solutions. J. Chem. Soc. Trans. 1910, 97, 2454-2463. The parts of $\mathrm{CsNO}_{3}$ in $100 \mathrm{~g}$ of water and specific gravity were cited from this literature, and the molality and molarity were calculated by using these parameters.

[26] Doan, T. H.; Sangster, J. Viscosities of concentrated aqueous solutions of some 1:1, 2:1 and 3:1 nitrates at $25^{\circ} \mathrm{C}$. J. Chem. Eng. Data 1981, 26, 141-144. The molality and density of $\mathrm{Mg}\left(\mathrm{NO}_{3}\right)_{2}$ were cited from this literature, and the molality was converted to the molarity by using the density.

[27] Pearce, J. N.; Blackman, L. E. The vapor pressures and activity coefficients of aqueous solutions of calcium and aluminum nitrates at $25^{\circ}$. J. Am. Chem. Soc. 1935, 57, 24-27. The molality and density of $\mathrm{Ca}\left(\mathrm{NO}_{3}\right)_{2}$ were cited from this literature, and the molality was converted to the molarity by using the density.

[28] Martínez-Andreu, A.; Vercher, E.; Peña, M. P. Apparent molar volumes of strontium nitrate and copper(II) chloride in ethanol + water at 298.15 K. J. Chem. Eng. Data 1999, 44, 86-92. 
The molarity and density of $\operatorname{Sr}\left(\mathrm{NO}_{3}\right)_{2}$ were cited from this literature, and the molarity was converted to the molality by using the density.

[29] Arnaud-Neu, F.; Delgado, R.; Chaves, S. Critical evaluation of stability constants and thermodynamic functions of metal complexes of crown ethers. Pure Appl. Chem. 2003, 75, 71-102.

[30] McConnell, A. J.; Beer, P. D. Heteroditopic receptors for ion-pair recognition. Angew. Chem. Int. Ed. 2012, 51, 5052-5061.

[31] Kim, S. K.; Sessler, J. L. Ion pair receptors. Chem. Soc. Rev. 2010, 39, 3784-3809.

[32] He, Q.; Vargas-Zúñiga, G. I.; Kim, S. H.; Kim, S. K.; Sessler, J. L. Macrocycles as ion pair receptors. Chem. Rev. 2019, 119, 9753-9835.

[33] Shannon, R. D.; Prewitt, C. T. Effective ionic radii in oxides and fluorides. Acta Crystallogr. 1969, B25, 925-946.

[34] Hadisaputra, S.; Pranowo, H. D.; Armunanto, R. Extraction of strontium(II) by crown ether: insights from density functional calculation. Indo. J. Chem., 2012, 12, 207-216.

[35] Lamb, J. D.; Izatt, R. M.; Swain, C. S.; Christensen, J. J. A systematic study of the effect of macrocyle ring size and donor atom type on the $\log K, \Delta H$, and $T \Delta S$ of reactions at $25{ }^{\circ} \mathrm{C}$ in methanol of mono- and divalent cations with crown ethers. J. Am. Chem. Soc. 1980, 102, 475-479.

[36] Lim, L. W.; Tokunaga, K.; Takeuchi, T. Development of chemically bonded crown ether stationary phases in capillary ion chromatography. Chromatography 2014, 35, 95-101. 